\title{
99mTc-Tilmanocept: A Novel Molecular Agent for Lymphatic Mapping and Sentinel Lymph Node Localization
}

\author{
Devaki Shilpa Surasi, Janis O’Malley, and Pradeep Bhambhvani \\ Division of Molecular Imaging and Therapeutics, Department of Radiology, University of Alabama at Birmingham, Birmingham, \\ Alabama \\ CE credit: For CE credit, you can access the test for this article, as well as additional JNMT CE tests, online at https://www.snmmilearningcenter.org. \\ Complete the test online no later than June 2018. Your online test will be scored immediately. You may make 3 attempts to pass the test and must \\ answer $80 \%$ of the questions correctly to receive $1.0 \mathrm{CEH}$ (Continuing Education Hour) credit. SNMMI members will have their CEH credit added to their \\ VOICE transcript automatically; nonmembers will be able to print out a CE certificate upon successfully completing the test. The online test is free to SNMMI \\ members; nonmembers must pay $\$ 15.00$ by credit card when logging onto the website to take the test.
}

Preoperative lymphatic mapping in conjunction with intraoperative $y$-probe detection is widely used for sentinel node localization in melanoma, breast cancer, and other malignancies. 99mTc-radiocolloids have been the standard radiotracers used for sentinel node mapping. ${ }^{99 m}$ Tc-tilmanocept is a receptorbinding molecular imaging agent approved by the U.S. Food and Drug Administration for lymphatic mapping and lymph node localization in breast cancer, melanoma, clinically nodenegative squamous cell carcinoma of the oral cavity, and other solid tumors. It has several advantages over conventional radiocolloids, including rapid injection site clearance, high sentinel node extraction, and low distal node accumulation, which can lead to efficient resource use.

Key Words: $99 \mathrm{mTc}$-tilmanocept; Lymphoseek; sentinel lymph node mapping; molecular imaging

J Nucl Med Technol 2015; 43:87-91

DOI: 10.2967/jnmt.115.155960

\section{$\mathbf{L}$}

ymphatic mapping with sentinel lymph node (SLN) localization has emerged as a valuable prognostic tool in the management of melanoma and early breast cancer. There are numerous definitions of an SLN based on location, lymphoscintigraphy interpretation, and use of a $\gamma$ detection probe or vital blue dye (VBD). Morton's original definition that a sentinel node is "the first lymph node that receives afferent lymphatic drainage from a primary tumor" best reflects the concept of stepwise spread of cancer (1). Nodal involvement has a significant impact on tumor staging, treatment, and prognosis. However, in breast cancer, most studies show no change in survival or only a slightly reduced survival in patients with nodal micrometastasis

Received Feb. 12, 2015; revision accepted Apr. 21, 2015.

For correspondence or reprints contact: Devaki Shilpa Surasi, Division of Molecular Imaging and Therapeutics, Department of Radiology, University of Alabama at Birmingham, 619 19th St. South, JT772, Birmingham, AL 35249-6835. E-mail: dsurasi@uabmc.edu

Published online May 8, 2015.

COPYRIGHT (c) 2015 by the Society of Nuclear Medicine and Molecular Imaging, Inc. compared with those without (2-4). Thus, lymphatic mapping and SLN localization have emerged as accurate and minimally invasive procedures for identifying clinically node-negative patients. Lymphatic mapping can be performed with radiotracers, VBD, or both. ${ }^{99 \mathrm{~m}} \mathrm{Tc}-$ labeled radiocolloids have traditionally been used in nodal mapping. In the United States, filtered ${ }^{99 \mathrm{~m}}$ Tc-sulfur colloid (SC) is most commonly used. The other tracers include 99m Tc-nanocolloid human serum albumin (Nanocoll; GE Healthcare) in Europe and ${ }^{99 \mathrm{~m}} \mathrm{Tc}$-antimony trisulfide in Australia and Canada (5). ${ }^{99 m}$ Tc-tilmanocept (Lymphoseek; Navidea) is a relatively new Food and Drug Administrationapproved receptor-targeted radiotracer for mapping and localization of lymph nodes draining breast cancer or melanoma. It is also approved to guide SLN biopsy in patients with clinically node-negative squamous cell carcinoma of the oral cavity. On October 15, 2014, the Food and Drug Administration approved the expanded use of ${ }^{99 m}$ Tc-tilmanocept for lymphatic mapping in solid tumors (6). ${ }^{99 \mathrm{~m} T c-}$ tilmanocept exhibits distinct advantages over radiocolloids, including rapid clearance of the injection site, high sentinel node extraction, and low distal node accumulation, which can lead to efficient use of resources in the clinic (5). This article reviews and summarizes the existing data on this new receptor-binding molecular imaging agent.

\section{THE IDEAL RADIOTRACER}

An ideal lymph node imaging agent would exhibit rapid clearance from the injection site, rapid uptake and high retention within the first draining lymph node, and low uptake by distal lymph nodes (7). The commonly used

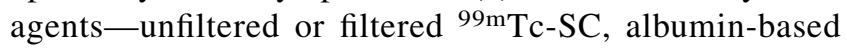
colloids, and ${ }^{99 \mathrm{~m}} \mathrm{Tc}$-antimony trisulfide colloid-do not exhibit all these characteristics. Furthermore, the ideal agent should have low radiation absorption, high biologic safety, rapid and stable ${ }^{99 \mathrm{~m}} \mathrm{Tc}$ labeling, and radiochemical purity (8). Vera et al. reported the synthesis and preliminary biologic testing of a synthetic macromolecule, ${ }^{99 \mathrm{~m}} \mathrm{Tc}-$ diethylenetriaminepentaacetic acid (DTPA)-mannosyl-dextran 


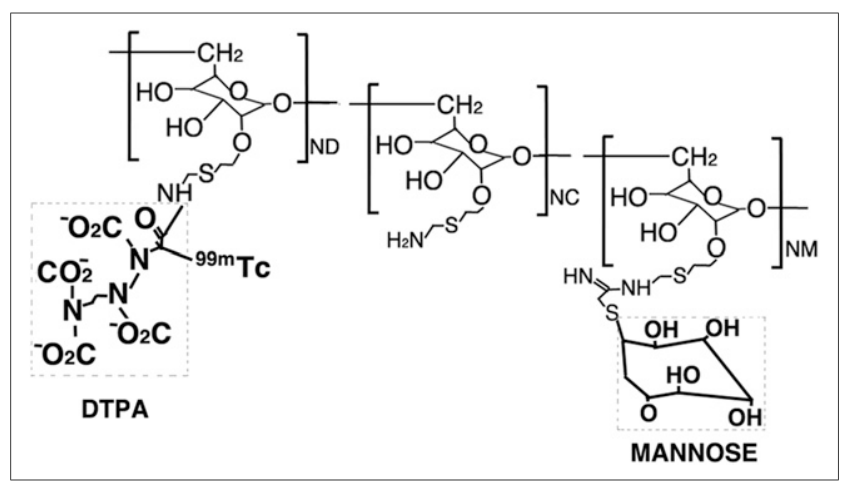

FIGURE 1. Molecular structure of $99 \mathrm{mTc}$-tilmanocept. It is composed of a dextran backbone to which multiple units of mannose and DTPA are attached. DTPA units serve as attachment sites for radioactive labeling with $99 \mathrm{~m} T \mathrm{~T}$. Mannose units provide a molecular mechanism by which ${ }^{99 m}$ Tc-tilmanocept binds to CD206 receptor specific to reticuloendothelial cells.

(the same as ${ }^{99 \mathrm{~m}} \mathrm{Tc}$-tilmanocept), for sentinel node detection and found that it exhibited the desired properties of rapid clearance from the injection site and low accumulation in distal nodes (9).

\section{MTC-TILMANOCEPT}

\section{Description of the Agent}

${ }^{99 m}$ Tc-tilmanocept is a novel radiopharmaceutical designed to overcome certain limitations of the conventionally used radiocolloids. It accumulates in lymphatic tissue by selectively targeting and binding to CD206 receptors on the surface of macrophages and dendritic cells, which are found in high concentration in lymph nodes (10). Tilmanocept is DTPA-mannosyl-dextran, a macromolecule with an average diameter of $7 \mathrm{~nm}$. It consists of multiple units of DTPA and mannose, each covalently attached to a dextran backbone (Fig. 1). The mannose acts as a ligand for the CD206 receptor, and the DTPA moieties serve as the binding site for ${ }^{99 \mathrm{~m}} \mathrm{Tc}$. Its small size allows rapid lymphatic uptake, and the targeted receptor binding on macrophages and dendritic cells in lymph nodes limits its migration into the distal nodes (9). In contrast to ${ }^{99 \mathrm{~m}} \mathrm{Tc}$-tilmanocept, unfiltered ${ }^{99 \mathrm{~m}} \mathrm{Tc}-\mathrm{SC}$ particles have an average size ranging from 305 to $340 \mathrm{~nm}$. Filtered ${ }^{99 \mathrm{~m}} \mathrm{Tc}-\mathrm{SC}$ particles are mostly between 100 and $220 \mathrm{~nm}$, whereas ${ }^{99 \mathrm{~m} T c-n a n o c o l l o i d ~ h u-}$ man serum albumin and ${ }^{99 \mathrm{~m}} \mathrm{Tc}$-antimony trisulfide particles range from 5 to $100 \mathrm{~nm}$ and 3 to $30 \mathrm{~nm}$, respectively (11).

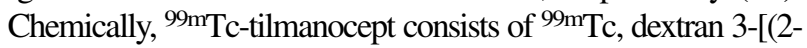
aminoethyl)thio]propyl-17-carboxy-10,13,16-tris(carboxymethyl)8-oxo-4-thia-7,10,13,16-tetraazaheptadec-1-yl-3-[[2-[[1-imino2-(D-mannopyranosylthio)ethyl]amino]ethyl]thio]propyl ether complexes. ${ }^{99 \mathrm{~m}} \mathrm{Tc}$-tilmanocept is supplied as a kit that is stored at room temperature and prepared by radiolabeling with ${ }^{99 \mathrm{~m}} \mathrm{Tc}$ and diluting with the supplied diluent before use. Each vial provides doses for up to 4 patients. Some clinics may rely on private radiopharmacies to supply a prepared dose.

The recommended dose of ${ }^{99 m} \mathrm{Tc}$-tilmanocept is 18.5 $\mathrm{MBq}(0.5 \mathrm{mCi})$ as a radioactivity dose and $50 \mu \mathrm{g}$ as a mass dose, administered at least 15 min before initiating intraoperative lymphatic mapping. Lymphatic mapping should be completed within $15 \mathrm{~h}$ of ${ }^{99 \mathrm{~m} T c-t i l m a n o c e p t}$ injection. The route of administration depends on the tumor location and the protocol of the clinic. Administration routes include intradermal and subcutaneous for breast cancer and melanoma, as well as subareolar and peritumoral for breast cancer. Injection volumes range from 0.1 to $1 \mathrm{~mL}$ given in a single injection or multiple injections depending on the indication and route of administration (10). Example ${ }^{99 \mathrm{~m}} \mathrm{Tc}-$ tilmanocept images are shown in Figures 2-4.

The radiation exposure associated with ${ }^{99 \mathrm{~m}} \mathrm{Tc}$-tilmanocept lymphatic mapping is relatively low. The estimated effective dose equivalent from an $18.5-\mathrm{MBq}(0.5-\mathrm{mCi})$ dose of ${ }^{99 \mathrm{~m}} \mathrm{Tc}$-tilmanocept in women with breast cancer and melanoma are 0.3302 and $0.2511 \mathrm{mSv}$, respectively, and the effective dose equivalent in men with the same diagnoses is 0.296 and $0.2024 \mathrm{mSv}$, respectively (10). For comparison, the average effective dose equivalent reported with other diagnostic studies such as mammography is $0.4 \mathrm{mSv}$ and that for 2-view chest radiography is $0.1 \mathrm{mSv}$ (12).

99m Tc-tilmanocept has no contraindications, and in clinical trials no serious adverse or hypersensitivity reactions were reported. However, there may be a risk of allergic reactions due to its chemical similarity to dextran. The most common adverse reactions included injection site irritation or pain, which occurred in less than $1 \%$ of patients. In animal studies, locally injected anesthetics have been reported to reduce lymphatic flow. Coinjection (mixture) of local anesthetics with ${ }^{99} \mathrm{~m}$ Tc-tilmanocept is not recommended and may impair the lymph node mapping. A review of clinical data did not identify any differences in safety or efficacy between elderly (65-90 y old) and younger (18-65 y old) patients (10).

\section{Preclinical Studies}

The potential application of ${ }^{99 \mathrm{~m}} \mathrm{Tc}$-tilmanocept to other cancers (e.g., gastric, colon, and prostate), along with demonstration of an acceptable biodistribution, lack of toxicity, low absorbed radiation dose, and favorable pharmacokinetic properties (faster injection site clearance, rapid accumulation, and longer retention in the sentinel node), have been reported in preclinical studies.

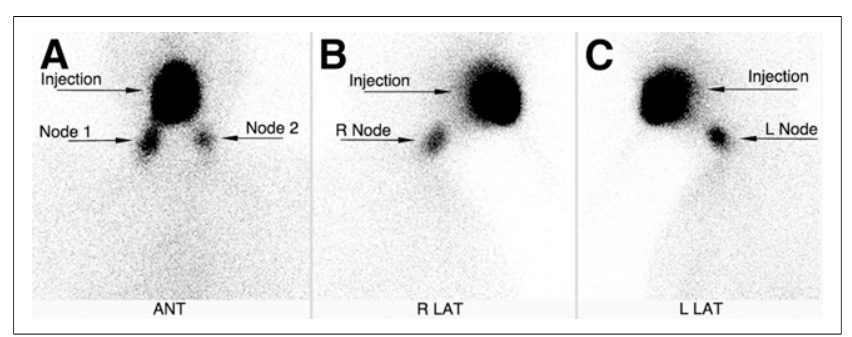

FIGURE 2. Squamous cell carcinoma in floor of mouth. ${ }^{99 m T c-}$ tilmanocept was injected at tumor site, and anterior cervical nodes were visualized bilaterally. ANT = anterior; LAT $=$ lateral. 


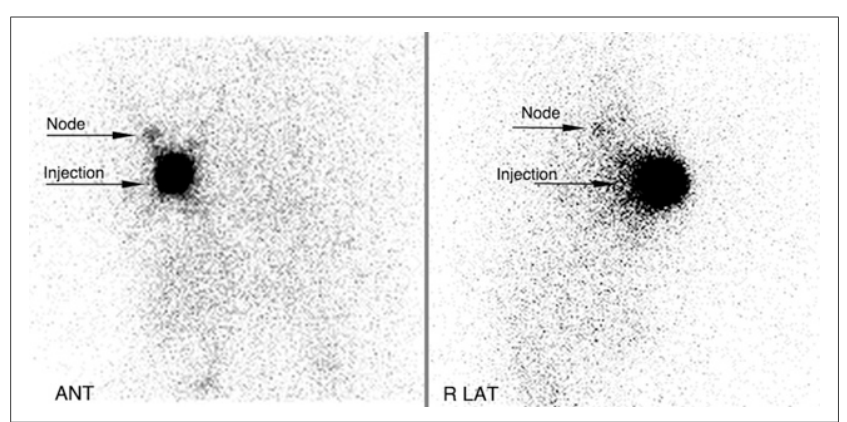

FIGURE 3. Cancer in right breast. After periareolar intradermal injection of $99 \mathrm{mTc}$-tilmanocept in right upper outer quadrant, sentinel node was identified in right axilla. ANT $=$ anterior; LAT $=$ lateral.

Readers are directed to the referenced articles for further details $(9,13-16)$.

\section{9mTc-Tilmanocept Versus ${ }^{99 m}$ Tc-SC}

Multiple phase I-III trials and retrospective studies have demonstrated the superior performance of ${ }^{99 \mathrm{~m} T c-t i l m a n o-}$ cept over filtered ${ }^{99 \mathrm{~m}} \mathrm{Tc}-\mathrm{SC}$.

A phase I clinical trial comparing ${ }^{99 m}$ Tc-tilmanocept with filtered ${ }^{99 \mathrm{~m}} \mathrm{Tc}-\mathrm{SC}$ for sentinel node detection was performed on 12 patients with breast cancer using peritumoral/ subdermal injections at the 3-, 6-, 9-, and 12-o'clock positions and acquisition of serial images for $180 \mathrm{~min}$. Sentinel nodes, excised within 4.2-7.3 h of administration, were assayed in a dose calibrator. ${ }^{99 \mathrm{~m} T c-t i l m a n o c e p t ~ e x h i b i t e d}$ a significantly faster injection site clearance $(P=0.0025)$ and equivalent primary sentinel node uptake $(P=0.75)$. The mean ${ }^{99 \mathrm{~m} T c-t i l m a n o c e p t}$ clearance half-time was $2.72 \pm 1.57 \mathrm{~h}$, compared with $49.5 \pm 38.5 \mathrm{~h}$ for filtered ${ }^{99 \mathrm{~m} T c-S C}$ (17). Faster injection site clearance and equivalent sentinel node uptake were similarly demonstrated in another phase I trial also in breast cancer patients but with an intradermal injection technique. The intradermal injection, however, did not exhibit a faster clearance half-time than peritumoral/subdermal injection (18). A similar phase I trial by the same group, performed on melanoma patients, also found that ${ }^{99 \mathrm{~m}} \mathrm{Tc}$-tilmanocept demonstrated faster injection site clearance and equivalent primary sentinel node uptake when compared with filtered ${ }^{99 \mathrm{~m} T c-S C}(7)$.

The efficacy of ${ }^{99 \mathrm{~m}}$ Tc-tilmanocept in 2-d lymphatic mapping protocols for breast cancer patients has also been proven. A study measuring injection site clearance and SLN accumulation after a single intradermal injection of ${ }^{99 \mathrm{~m}} \mathrm{Tc}$-tilmanocept and ${ }^{99 \mathrm{~m}} \mathrm{Tc}-\mathrm{SC}$ using a 2 -d protocol found that ${ }^{99 \mathrm{~m}} \mathrm{Tc}$-tilmanocept cleared from the injection site significantly faster than ${ }^{99 \mathrm{~m} T c-}$ SC $(P<0.001)$. The mean SLN uptake of ${ }^{99 m}$ Tc-tilmanocept was statistically equivalent to that of ${ }^{99 \mathrm{~m} T c-S C}(P=0.213)$. The extended interval provided by the 2-d protocol demonstrated that SLN accumulation of ${ }^{99 \mathrm{~m}} \mathrm{Tc}$-tilmanocept can persist for at least $24 \mathrm{~h}$ after administration (19). A retrospective analysis of 32 breast cancer patients also found that although the clearance rate of ${ }^{99 \mathrm{~m} T c-t i l m a n o c e p t}$ was faster than that of filtered ${ }^{99 \mathrm{~m}} \mathrm{Tc}-\mathrm{SC}$, there was no significant difference between the 2 radiopharmaceuticals for the detection of radioactive SLNs in 2-d breast lymphatic mapping procedures (20).

A phase I study testing the biodistribution and safety of ${ }^{99 m}$ Tc-tilmanocept at different molar doses was performed on 24 breast cancer patients by Ellner et al. (21). Patients were categorized into 4 groups: 3 different molar doses of ${ }^{99 \mathrm{~m} T c-t i l m a n o c e p t}(0.2,1.0$, or $5.0 \mathrm{nmol})$ and a dose of filtered ${ }^{99 \mathrm{~m}} \mathrm{Tc}-\mathrm{SC}$. They found that the injection site clearance of ${ }^{99 \mathrm{~m}} \mathrm{Tc}$-tilmanocept was not statistically different in a dose-dependent manner; however, dose-dependent sentinel node uptake was observed $(P=0.03)$. These findings also led to the selection of $1 \mathrm{nmol}$ as the optimal molar dose. No clinically significant changes were seen in laboratory parameters among any of the dose levels at 4 or $24 \mathrm{~h}$ after injection, compared with preoperative levels. Absorbed radiation doses did not differ among the three ${ }^{99 \mathrm{~m}} \mathrm{Tc}$-tilmanocept dose levels but were lower than for filtered ${ }^{99 \mathrm{~m}} \mathrm{Tc}-\mathrm{SC}$.

Baker et al. evaluated the technical outcomes of SLN biopsy in breast cancer patients mapped with ${ }^{99 \mathrm{~m} T c-t i l m a-}$ nocept and VBD versus filtered ${ }^{99 \mathrm{~m}} \mathrm{Tc}-\mathrm{SC}$ and VBD. They found that fewer SLNs were removed from patients mapped with ${ }^{99 \mathrm{~m} T c-t i l m a n o c e p t}$ plus VBD than from patients receiving filtered ${ }^{99 \mathrm{~m} T c-S C}$ plus VBD $(P<0.001)$. Similar proportions of patients were identified with pathologic node involvement, whether mapped with ${ }^{99 \mathrm{~m} T c-t i l m a n o c e p t}$ or with filtered ${ }^{99 \mathrm{~m}} \mathrm{Tc}-\mathrm{SC}$. However, in the ${ }^{99 \mathrm{~m}} \mathrm{Tc}$-tilmanocept group, a larger proportion of removed nodes were found to be positive (1.7 times greater) (22).

A prospective phase II clinical trial on 31 breast cancer and 47 cutaneous melanoma patients demonstrated the safety and efficacy of ${ }^{99 \mathrm{~m} T c-t i l m a n o c e p t ~ i n ~ i n t r a o p e r a t i v e ~}$

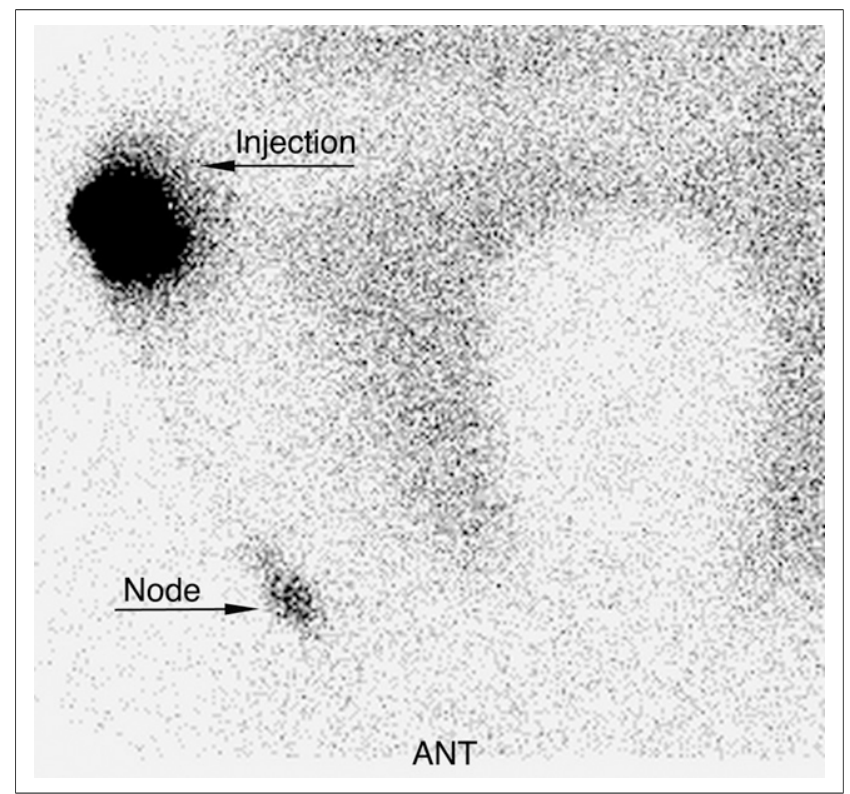

FIGURE 4. Melanoma in right arm. After intradermal injection of $99 \mathrm{~m}$ Tc-tilmanocept around lesion, sentinel node was identified in right axilla. 
lymphatic mapping. Lymphoscintigraphy identified a hot spot in $94.5 \%$ of patients before surgery. Intraoperatively, at least one regional SLN was identified in $96.2 \%$ of patients. In addition to high per-patient localization rates, ${ }^{99 \mathrm{~m}} \mathrm{Tc}$-tilmanocept exhibited mapping sensitivity of $95.1 \%$ (resected tissues) and tissue specificity of $100 \%$ (lymph nodes). The overall proportion of ${ }^{99 \mathrm{~m}}$ Tc-tilmanocept-positive lymph nodes containing metastatic disease was $13.7 \%$. Five procedurerelated serious adverse events occurred, none of which were related to ${ }^{99 \mathrm{~m}}$ Tc-tilmanocept (23).

Two nonrandomized phase III trials, in which 15 centers contributed 154 patients, compared ${ }^{99 m}$ Tc-tilmanocept with VBD for identification of the SLN in clinically node-negative cutaneous melanoma. The primary endpoints included concordance (proportion of blue nodes detected by ${ }^{99 \mathrm{~m}}$ Tc-tilmanocept; $90 \%$ was the prespecified minimum concordance level) and reverse concordance (the proportion of radioactive nodes detected by VBD). Intraoperatively, 232 of 235 blue nodes were detected by ${ }^{99 \mathrm{~m}}$ Tc-tilmanocept, for $98.7 \%$ concordance $(P<0.001) .{ }^{99 \mathrm{~m} T c-t i l m a n o c e p t}$ detected 364 nodes, of which 232 were detected by VBD, for a $63.7 \%$ reverse concordance. Melanoma was identified in the SLNs of $22.1 \%$ of patients. ${ }^{99 m}$ Tc-tilmanocept identified more SLNs in more patients and identified more melanoma-containing nodes than VBD, with no serious adverse events attributed to ${ }^{99 \mathrm{~m} T c-t i l m a n o c e p t}(24)$. A similar phase III study for SLN mapping was performed on breast cancer patients. Intraoperatively, 207 of 209 nodes detected by VBD were also detected by ${ }^{99 \mathrm{~m}}$ Tc-tilmanocept, for a concordance rate of $99.04 \%(P<0.0001)$. ${ }^{99 m}$ Tc-tilmanocept detected 320 nodes, of which 207 (64.7\%, reverse concordance) were detected by VBD. Metastatic disease was identified in the SLNs of $18.2 \%$ of patients. More SLNs in more patients with a higher number of metastatic lymph nodes were identified by ${ }^{99 \mathrm{~m}}$ Tc-tilmanocept than by VBD (25).

\section{9mTc-Tilmanocept Versus ${ }^{99 m T c-N a n o c o l l o i d ~ H u m a n ~}$ Serum Albumin}

${ }^{99} \mathrm{~m}$ Tc-nanocolloid human serum albumin is a widely used radiocolloid in Europe, often in conjunction with VBD. Tokin et al. retrospectively compared ${ }^{99 \mathrm{~m}}$ Tc-tilmanocept with ${ }^{99 \mathrm{~m}} \mathrm{Tc}$-nanocolloid human serum albumin in breast cancer patients who underwent intraoperative lymphatic mapping. Data analysis revealed a higher localization rate (proportion of patients with at least one localized lymph node) and degree of localization (average number of localized nodes per patient relative to patient population) for ${ }^{99 m}$ Tc-tilmanocept than for ${ }^{99 m}$ Tc-nanocolloid human serum albumin $(P<0.0001)(8)$.

\section{9mTc-Tilmanocept in Oral Cavity Squamous Cell Carcinoma}

SLN biopsy for early-stage oral cavity cancer has decreased treatment morbidity and cost. It is gaining acceptance as an effective alternative to elective neck dissection for staging the N0 neck (26). Though several studies showing the utility of ${ }^{99 \mathrm{~m}} \mathrm{Tc}$-tilmanocept in breast carcinoma and melanoma are available, only a few studies have outlined its role in detection of SLNs in oral cavity squamous cell carcinoma. A preliminary single-institution experience within the setting of a phase III multi-institutional study, reported by Marcinow et al., demonstrated a high negative predictive value and low false-negative rate in the identification of occult nodal metastases in head and neck squamous cell carcinoma using ${ }^{99 \mathrm{~m}} \mathrm{Tc}$-tilmanocept (27). They also compared planar imaging with SPECT/CT and found that SPECT/CT identified additional SLNs in 55\% of the cases, thus improving preoperative SLN localization, including delineation of SLN locations near the primary tumor. The trial was terminated early on the basis of an interim review by the Data and Safety Monitoring Committee for positive efficacy outcome and no safety concerns.

A recent multicenter, open-label, phase III trial by Agrawal et al. found a high rate of SLN identification with the use of ${ }^{99 m}$ Tc-tilmanocept SLN biopsy in patients with intraoral or cutaneous head and neck squamous cell carcinoma. When used with serial sectioning and immunohistochemistry, SLN biopsy with ${ }^{99 \mathrm{~m}}$ Tc-tilmanocept accurately predicted the pathologic status in neck nodes, with a low false-negative rate, high negative predictive value, and high overall accuracy, potentially avoiding more extensive surgery, including elective neck dissection (28).

Superior performance characteristics for ${ }^{99 \mathrm{~m}} \mathrm{Tc}$-tilmanocept in intraoperative lymphatic mapping have also been demonstrated in a cohort of 384 patients with multiple solid tumors, including breast cancer, melanoma (all sites), and head and neck squamous cell carcinoma (cutaneous and oral [tongue, floor-of-mouth, gingiva, and lip]) (29-32).

\section{Reimbursement}

For the imaging procedure, SNMMI recommends Current Procedural Terminology code 78195 (lymphatic and lymph node imaging) for all settings and payers. When ${ }^{99 m}$ Tc-tilmanocept is injected for lymph node mapping without imaging, the Current Procedural Terminology code to be used is 38792 (injection procedure; radioactive tracer for identification of sentinel node). Since January 1, 2014, the additional specific drug code for ${ }^{99 \mathrm{~m} T c-t i l m a n o c e p t, ~ d i-}$ agnostic, up to $18.5 \mathrm{MBq}(0.5 \mathrm{mCi})$, is Healthcare Common Procedure Coding System level II code A9520 (33). According to the Medicare Hospital Outpatient Prospective Payment System, the proposed 2015 rates for codes 78195 , 38792 , and A9520 are $\$ 363.90, \$ 285.47$, and $\$ 240$, respectively (34).

\section{CONCLUSION}

Preoperative and intraoperative lymphatic mapping with 99mTc-tilmanocept, a Food and Drug Administrationapproved agent based on receptor targeting, provides a novel and clinically valuable approach to complement oncologic surgery. The safety and superior efficacy profile of 99m Tc-tilmanocept in comparison to the traditionally used radiotracers has been demonstrated in several preclinical 
and clinical studies. The main advantages include rapid injection site clearance, high sentinel node extraction, and low distal node accumulation.

\section{DISCLOSURE}

No potential conflict of interest relevant to this article was reported.

\section{REFERENCES}

1. Nieweg OE, Tanis PJ, Kroon BB. The definition of a sentinel node. Ann Surg Oncol. 2001;8:538-541.

2. Gobardhan PD, Elias SG, Madsen EV, et al. Prognostic value of micrometastases in sentinel lymph nodes of patients with breast carcinoma: a cohort study. Ann Oncol. 2009;20:41-48.

3. Andersson Y, Frisell J, Sylvan M, de Boniface J, Bergkvist L. Breast cancer survival in relation to the metastatic tumor burden in axillary lymph nodes. $J$ Clin Oncol. 2010;28:2868-2873.

4. Weaver DL, Ashikaga T, Krag DN, et al. Effect of occult metastases on survival in node-negative breast cancer. $N$ Engl J Med. 2011;364:412-421.

5. Woehnl A, Hoh C, Méndez J, et al. Molecular imaging of the sentinel lymph node via Lymphoseek. In: Leong S, ed. From Local Invasion to Metastatic Cancer: Involvement of Distant Sites Through the Lymphovascular System. New York, NY: Springer; 2009:123-133.

6. FDA approves expanded use of Navidea's Lymphoseek ${ }^{\circledR}$ for lymphatic mapping in solid tumors [press release]. Navidea website. http://ir.navidea.com/phoenix.zhtml? $\mathrm{c}=68527 \& \mathrm{p}=$ irol-newsArticle $\& \mathrm{ID}=1977807$. Published October 15, 2014. Accessed April 23, 2015.

7. Wallace AM, Hoh CK, Ellner SJ, Darrah DD, Schulteis G, Vera DR. Lymphoseek: a molecular imaging agent for melanoma sentinel lymph node mapping. Ann Surg Oncol. 2007;14:913-921.

8. Tokin CA, Cope FO, Metz WL, et al. The efficacy of tilmanocept in sentinel lymph mode mapping and identification in breast cancer patients: a comparative review and meta-analysis of the ${ }^{99 \mathrm{~m}}$ Tc-labeled nanocolloid human serum albumin standard of care. Clin Exp Metastasis. 2012;29:681-686.

9. Vera DR, Wallace AM, Hoh CK, Mattrey RF. A synthetic macromolecule for sentinel node detection: ${ }^{99 \mathrm{~m}}$ Tc-DTPA-mannosyl-dextran. J Nucl Med. 2001;42:951959.

10. Lymphoseek prescribing information. Lymphoseek website. http://lymphoseek. com/assets/pdfs/Lymphoseek\%20Package\%20Insert\%20-\%20October\%202014. pdf. Published 2013. Revised September 2014. Accessed April 23, 2015.

11. Giammarile F, Alazraki N, Aarsvold JN, et al. The EANM and SNMMI practice guideline for lymphoscintigraphy and sentinel node localization in breast cancer. Eur J Nucl Med Mol Imaging. 2013;40:1932-1947.

12. Mettler FA Jr, Huda W, Yoshizumi TT, Mahesh M. Effective doses in radiology and diagnostic nuclear medicine: a catalog. Radiology. 2008;248:254-263.

13. Hoh CK, Wallace AM, Vera DR. Preclinical studies of [ $\left.{ }^{99 \mathrm{~m}} \mathrm{Tc}\right] \mathrm{DTPA}-\mathrm{mannosyl-}$ dextran. Nucl Med Biol. 2003;30:457-464.

14. Ellner SJ, Mendez J, Vera DR, Hoh CK, Ashburn WL, Wallace AM. Sentinel lymph node mapping of the colon and stomach using Lymphoseek in a pig model. Ann Surg Oncol. 2004;11:674-681.

15. Méndez J, Wallace AM, Hoh CK, Vera DR. Detection of gastric and colonic sentinel nodes through endoscopic administration of ${ }^{99 m}$ Tc-DTPA-mannosyldextran in pigs. $J$ Nucl Med. 2003;44:1677-1681.

16. Wallace AM, Ellner SJ, Mendez J, et al. Minimally invasive sentinel lymph node mapping of the pig colon with Lymphoseek. Surgery. 2006;139:217-223.

17. Wallace AM, Hoh CK, Vera DR, Darrah DD, Schulteis G. Lymphoseek: a molecular radiopharmaceutical for sentinel node detection. Ann Surg Oncol. 2003; 10:531-538.
18. Wallace AM, Hoh CK, Darrah DD, Schulteis G, Vera DR. Sentinel lymph node mapping of breast cancer via intradermal administration of Lymphoseek. Nucl Med Biol. 2007;34:849-853.

19. Wallace AM, Hoh CK, Limmer KK, Darrah DD, Schulteis G, Vera DR. Sentinel lymph node accumulation of Lymphoseek and Tc-99m-sulfur colloid using a "2day" protocol. Nucl Med Biol. 2009;36:687-692.

20. Khandekar S, Neumann D, Amin K, DiFilippo F. Comparison of Tc 99m-tilmanocept and filtered Tc $99 \mathrm{~m}$-sulfur colloid for breast lymphatic mapping [abstract]. J Nucl Med. 2014;55(suppl):2522.

21. Ellner SJ, Hoh CK, Vera DR, Darrah DD, Schulteis G, Wallace AM. Dosedependent biodistribution of [ $\left.{ }^{99 \mathrm{~m}} \mathrm{Tc}\right] \mathrm{DTPA}-\mathrm{mannosyl}-\mathrm{dex}$ tran for breast cancer sentinel lymph node mapping. Nucl Med Biol. 2003;30:805-810.

22. Baker JL, Pu M, Tokin CA, et al. Comparison of ${ }^{99 m}$ Tc-tilmanocept and filtered ${ }^{99 \mathrm{~m} T c-s u l f u r}$ colloid for identification of SLNs in breast cancer patients. Ann Surg Oncol. 2015;22:40-45.

23. Leong SP, Kim J, Ross M, et al. A phase 2 study of ${ }^{99 m}$ Tc-tilmanocept in the detection of sentinel lymph nodes in melanoma and breast cancer. Ann Surg Oncol. 2011;18:961-969.

24. Sondak VK, King DW, Zager JS, et al. Combined analysis of phase III trials evaluating [ ${ }^{99 m}$ Tc]tilmanocept and vital blue dye for identification of sentinel lymph nodes in clinically node-negative cutaneous melanoma. Ann Surg Oncol. 2013;20:680-688.

25. Wallace AM, Han LK, Povoski SP, et al. Comparative evaluation of [ $\left.{ }^{99 \mathrm{~m}} \mathrm{Tc}\right]$ tilmanocept for sentinel lymph node mapping in breast cancer patients: results of two phase 3 trials. Ann Surg Oncol. 2013;20:2590-2599.

26. Monroe MM, Lai S. Sentinel lymph node biopsy for oral cancer: supporting evidence and recent novel developments. Curr Oncol Rep. 2014;16:385.

27. Marcinow AM, Hall N, Byrum E, Teknos TN, Old MO, Agrawal A. Use of a novel receptor-targeted (CD206) radiotracer, ${ }^{99 \mathrm{~m} T c-t i l m a n o c e p t, \text { and SPECT/ }}$ $\mathrm{CT}$ for sentinel lymph node detection in oral cavity squamous cell carcinoma: initial institutional report in an ongoing phase 3 study. JAMA Otolaryngol Head Neck Surg. 2013;139:895-902.

28. Agrawal A, Civantos FJ, Brumund KT, et al. Tc-tilmanocept accurately detects sentinel lymph nodes and predicts node pathology status in patients with oral squamous cell carcinoma of the head and neck: results of a phase III multiinstitutional trial. Ann Surg Oncol. February 11, 2015 [Epub ahead of print].

29. Reininger C, Shuping J, Metz W, et al. A pooled assessment of the per patient negative predictive value $(\mathrm{NPV} ; \mathrm{n}=286)$ and positive predictive value (PPV; $\mathrm{n}=98$; based on histological localization) for patients with breast cancer or melanoma or squamous cell carcinoma of the head/neck (cutaneous and oral) shows that no single metric has less than 99-percent performance for CD206targeted ${ }^{99 m}$ Tc-tilmanocept [abstract]. J Nucl Med. 2014;55(suppl):571.

30. Blue M, Metz W, Shuping J, et al. CD206 receptor-targeted 99m Tc-tilmanocept ( $\mathrm{TcTm}$ ) is equally effective in detection of sentinel lymph nodes (SLNs) in breast cancer (BC), melanoma (ME), and head/neck squamous cell carcinoma (HNSCC) with $>=99 \%$ accuracy [abstract]. J Nucl Med. 2014;55(suppl):1528.

31. Cope F, Metz W, Shuping J, et al. The high sensitivity (SEN) of ${ }^{99 \mathrm{~m}} \mathrm{Tc}$-tilmanocept $(\mathrm{TcTm})$ is unaffected by injection route and interval from injection to surgery across solid tumor types [abstract]. J Nucl Med. 2014;55(suppl):1554.

32. Abbruzzese B, Shuping J, Metz W, et al. A pooled assessment of 384 patients with breast cancer, melanoma or squamous cell carcinoma of the head/neck (cutaneous and oral) shows a false negative rate for identifying pathologypositive lymph nodes of less than two-percent when CD206 receptor-targeted ${ }^{99 m}$ Tc-tilmanocept is used as a single agent [abstract]. J Nucl Med. 2014;55 (suppl):655.

33. LymphoSeek ${ }^{\circledR}$ (technetium Tc 99m tilmanocept). SNMMI website. http://www. snmmi.org/ClinicalPractice/QandADetail.aspx? ItemNumber $=1894$. Accessed April 23, 2015.

34. Final 2014 compared to final 2015 rates: Medicare Hospital Outpatient Prospective Payment System HOPPS (APC)—nuclear medicine procedures, radiopharmaceuticals, and drugs. SNMMI website. http://snmmi.files.cms-plus.com/docs/hpra/ SNMMI\%20HOPPS\%202014F\%20vs.\%202015F.pdf. Accessed April 23, 2015. 